Article

\title{
Prescribing Innovation within a Large-Scale Restoration Programme in Degraded Subtropical Thicket in South Africa
}

\author{
Anthony J. Mills ${ }^{1, *}$, Marius van der Vyver ${ }^{2}$, Iain J. Gordon ${ }^{3}$, Anand Patwardhan ${ }^{4,5}$, \\ Christo Marais ${ }^{6}$, James Blignaut ${ }^{7}$, Ayanda Sigwela ${ }^{8}$ and Barney Kgope ${ }^{9}$
}

1 Department of Soil Science, Stellenbosch University, Matieland 7602, South Africa

2 Department of Botany, Nelson Mandela Metropolitan University, P.O. Box 77000, Port Elizabeth 6031 and Sigwela and Associates Environmental Consulting, P.O. Box 13099, East London 5247, South Africa; E-Mail: mariusvdv@gmail.com

3 James Hutton Institute, Invergowrie, Dundee, DD2 5DA, UK and James Cook University, Townsville 4811, Australia; E-Mail: iain.gordon@jcu.edu.au

4 School of Public Policy, University of Maryland, College Park, MD 20742, USA; E-Mail: apat@umd.edu

5 Shailesh J. Mehta School of Management, Indian Institute of Technology, Mumbai, 400076, India

6 Department of Environmental Affairs, Cape Town 8000, South Africa;

E-Mail: cmarais@environment.gov.za

7 Department of Economics, University of Pretoria, Pretoria 0002 and SAEON, The Woods, 41 De Havilland Crescent, Persequor Technopark, Pretoria 0020, South Africa;

E-Mail: jnblignaut@gmail.com

8 Sigwela and Associates Environmental Consulting, P.O. Box 13099, East London 5247, South Africa; E-Mail: nyathi@ecol.co.za

9 Department of Environmental Affairs, Environment House, Pretoria 0002, South Africa; E-Mail: bkgope@environment.gov.za

* Author to whom correspondence should be addressed; E-Mail: mills@sun.ac.za; Tel.: +27-21-715-1560; Fax: +27-21-712-8113.

Academic Editors: Mark S. Ashton and Eric J. Jokela

Received: 22 September 2015 / Accepted: 13 November 2015 / Published: 24 November 2015

Abstract: Commonly cited requirements for bridging the "science-practice divide" between
practitioners and scientists include: political support, communication and experimentation.
The Subtropical Thicket Restoration Programme was established in 2004 to catalyse
investment in large-scale restoration of degraded subtropical thicket in the Eastern Cape, 
South Africa. Political support has been strong, with the South African government investing more than US\$8 million into the programme. Communication occurred regularly among a wide range of stakeholders, and a restoration experiment-comprising 12 treatments and $\sim 300$ plots - was established over an area of $\sim 75,000 \mathrm{~km}^{2}$. Despite this support, communication and experimentation, many pitfalls were encountered. For example, one restoration protocol became entrenched in the programme's public as well as private sector operations without continual scrutiny of its efficacy. This was largely because results from the large-scale restoration experiment only emerged a decade after its conceptualization. As the programme enters its second decade there is recognition that a full range of "intelligent tinkering"-from small, rapid experiments to large, long-term experiments - needs to be planned and prescribed. The new working hypothesis is that prescribed innovation will reduce costs of restoration, increase survivorship of plants, increase income streams from restored landscapes, and promote new financing mechanisms for restoration.

Keywords: innovation; intelligent tinkering; large-scale restoration; Portulacaria afra; private sector; public-private partnerships

\section{Introduction}

In 2011 in Bonn, world leaders set the ambitious goal of restoring 150 million hectares of degraded forest land by 2020 [1]. The Aichi Biodiversity Target 15 within the Convention on Biological Diversity has a similar goal, namely the restoration of at least $15 \%$ of degraded ecosystems globally. Despite these objectives, there are only a few ecological restoration initiatives (e.g., the Mississippi Valley Project, the Atlantic Forest Restoration Pact, the Loess Plateau Watershed Restoration Project and the Shinyanga Soil Conservation Programme) [2-7] that operate at the scale of thousands of hectares let alone at the required scale of hundreds of thousands or even millions of hectares [8]. To meet the Bonn Challenge and the Aichi Target 15, many new large-scale restoration programmes will need to be established over the next few years. With this new international focus on upscaling restoration, ecologists are increasingly being asked to find ways to cross the well-recognized problem of a "science-practice" divide [9-13]. Practitioners, for example, often accuse scientific research of not being focused on topics that are of value to them, with the scientific outputs often being delayed and/or too narrowly focused.

In an editorial "Ecosystem restoration is now a global priority: time to roll up our sleeves", Aronson and Alexander 2013 [14] note that there are numerous obstacles and misconceptions afflicting restoration projects at large scales and that the old adage "nothing ventured, nothing gained" applies. Other authors have noted the importance of strong political support, effective communication between stakeholders, and rigorous applied science in supporting long-term restoration programmes [15-18]. Here we report on what was ventured, what was gained and what pitfalls were encountered over a decade of combining science and implementation to promote large-scale restoration of subtropical thicket in South Africa. We suggest that, in order to realize the ambitious Bonn Challenge and Aichi Target 15, cross-pollination of ideas and lessons learned from such large-scale restoration initiatives will need to be applied to other current, as well as planned, restoration programmes. 


\subsection{A Decade of Large-Scale Restoration in Subtropical Thicket, Eastern Cape, South Africa}

In 2004, the South African government (through its Expanded Public Works Programme (EPWP)) established the "Subtropical Thicket Restoration Programme" (STRP) to catalyse public, as well as private sector, investment in restoration of degraded landscapes (Figure 1) across the thicket biome in the Eastern Cape [19]. It was acknowledged at the outset that the main source of funding would ultimately need to be the private sector because the $\sim \$ 600$ million required for appropriate restoration of the 1.4 million ha of degraded thicket would be unaffordable for the South African government [19]. The assumption adopted by the STRP was that private sector investment could ultimately be attracted because restored, dense, thicket landscapes are inherently more productive in terms of generating economic benefits - from inter alia ecotourism, hunting, venison production, goat production, water production, beekeeping and carbon credit generation - than degraded landscapes [19,20]. It was, however, also noted within the STRP that in certain landscapes, where the risk of soil erosion is negligible, an open savanna-like ecosystem (although technically a degraded ecosystem) might be most appropriate for land uses such as ecotourism and production of livestock.

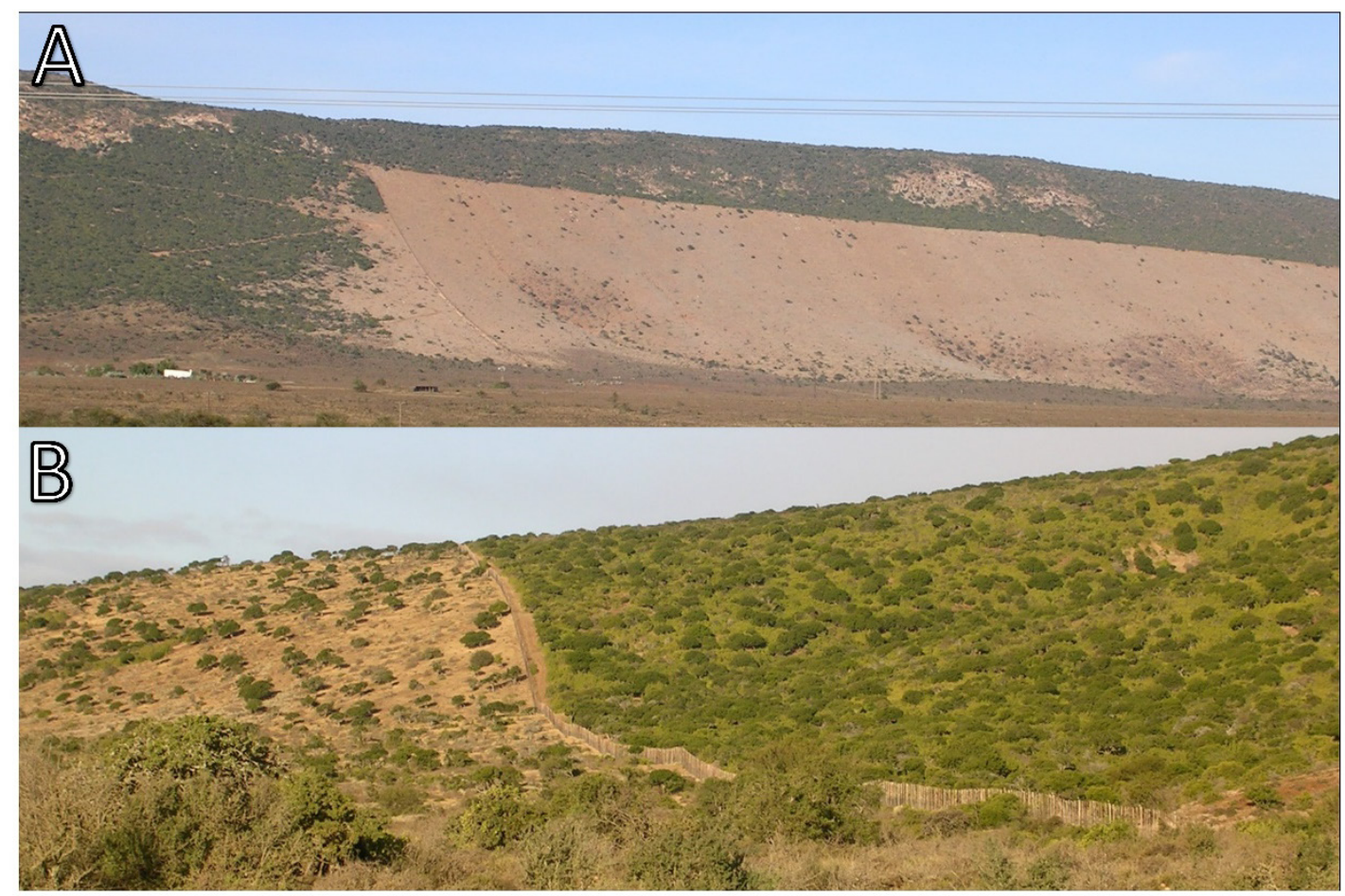

Figure 1. Fence-line contrasts of degraded versus intact subtropical thicket in the Eastern Cape, South Africa. (A) 45 km NE of Steytlerville; (B) $~ 80 \mathrm{~km} \mathrm{SE}$ of Steytlerville.

\subsection{How Science and Fortuitous Restoration Catalysed Funding for the STRP}

Subtropical thicket was chosen by the South African government as an appropriate ecosystem for investments into large-scale restoration for two main reasons. Firstly, a comprehensive study of the state of degradation of the thicket biome - which highlighted the extreme desertification that had occurred in this semi-arid ecosystem as a result of a century of injudicious goat farming - had recently been completed [21-23]. Secondly, a small-scale restoration trial undertaken from the 1970s by a land owner, 
Mr. Graham Slater, on his farm Krompoort (Figure 2), inadvertently provided a proof of concept that degraded thicket landscapes could be effectively restored [24] relatively inexpensively and that the restoration would sequester large amounts of carbon into soils and plants [25]. Other restoration initiatives have also reported on the value of such fortuitous restoration trials. For example, restoration in the Atlantic Forest region of Brazil has been informed by restoration initiatives going back more than 150 years. In particular, in the late nineteenth century, when the city of Rio de Janeiro faced water shortages because of the conversion of its original forests to agriculture, the Emperor Dom Pedro II ordered the planting of thousands of seedlings from 1862 to 1892 . This forest still stands today as the Tijuca Forest National Park [3].

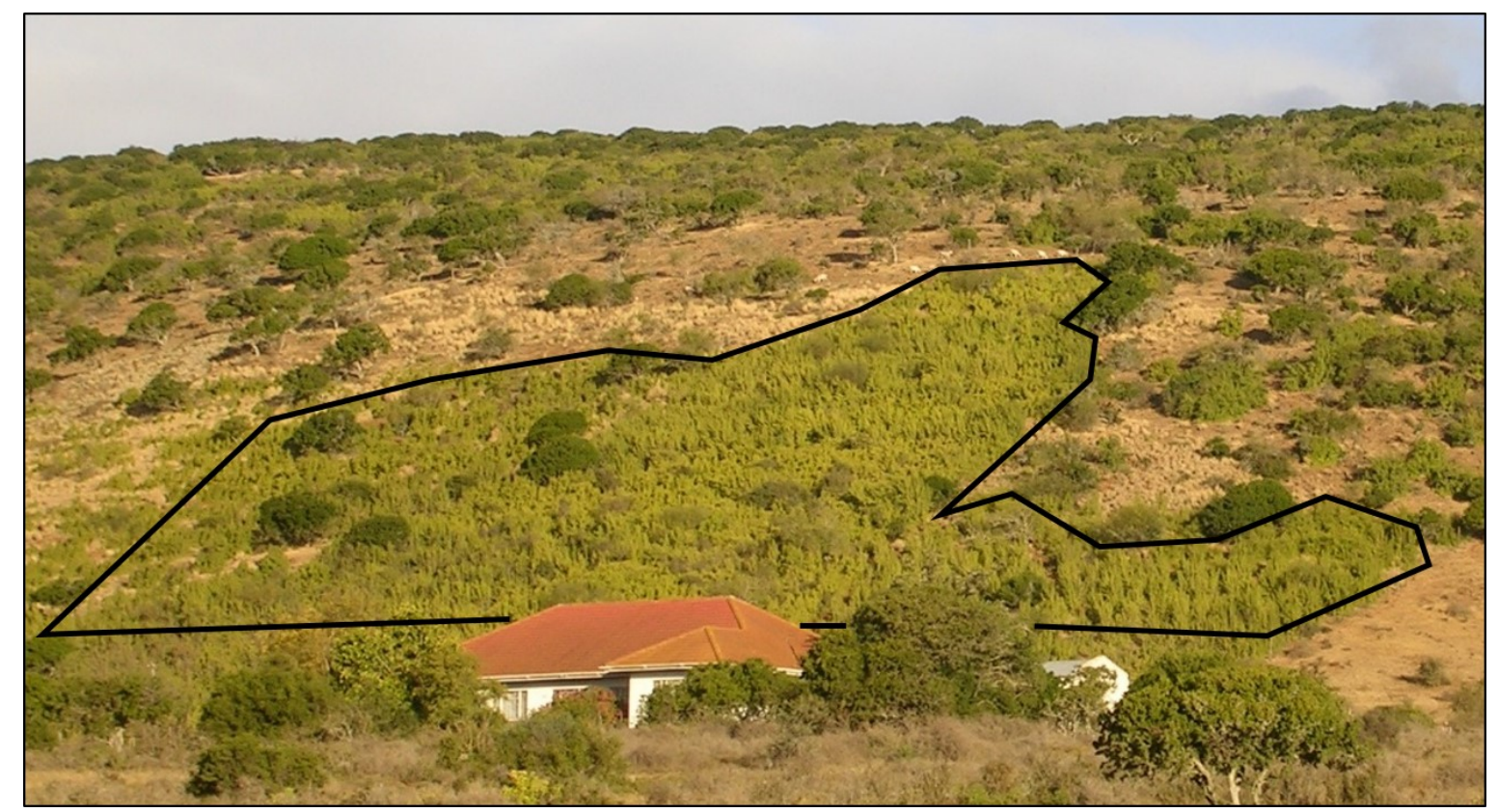

Figure 2. A degraded thicket hillslope that was, starting in the early 1970s, planted with spekboom cuttings over the course of three decades. Planted areas are those demarcated within the black lines. Location: Krompoort Farm, $\sim 86 \mathrm{~km}$ SE of Steytlerville, Eastern Cape, South Africa.

The history of the STRP's fortuitous restoration trial, by comparison, is as follows. In the 1970s, Mr Slater constructed a barn near his homestead, at the base of a degraded thicket hillslope. The flooding of the barn with silt-rich water after intense rain events was one of the reasons (G. Slater personal communication., November 2003) which led to Mr Slater planting the slope with cuttings of an indigenous succulent tree, Portulacaria afra (L.) Jacq.- - known locally as spekboom (Figure 3). The spekboom cuttings flourished, other plant species established naturally, and ultimately a dense thicket was formed over an area of $\sim 2.5$ ha, with a botanical composition and diversity similar to the pristine thicket [24].

$\mathrm{Mr}$ Slater also reported that the flooding stopped shortly after the establishment of the spekboom cuttings. He was so pleased with the aesthetic result of transforming a brown, degraded thicket hillslope into a dense, green thicket — as well as the extra fodder that this slope now provided for his goats during the kidding period - that he continued to plant spekboom cuttings until the late 1990s. He noted that planting spekboom cuttings was an extremely effective way of restoring the thicket ecosystem because 
the method (i) did not require a nursery and was, therefore, relatively inexpensive; (ii) was as simple as digging a hole and planting a cutting into it; and (iii) resulted in minimal mortality of cuttings even in years of severe drought. In hindsight, Mr Slater, was an early pioneer of "ecosystem-based adaptation" [26] in that he was restoring an ecosystem to reduce the risks of extreme weather events, including floods as well as drought.

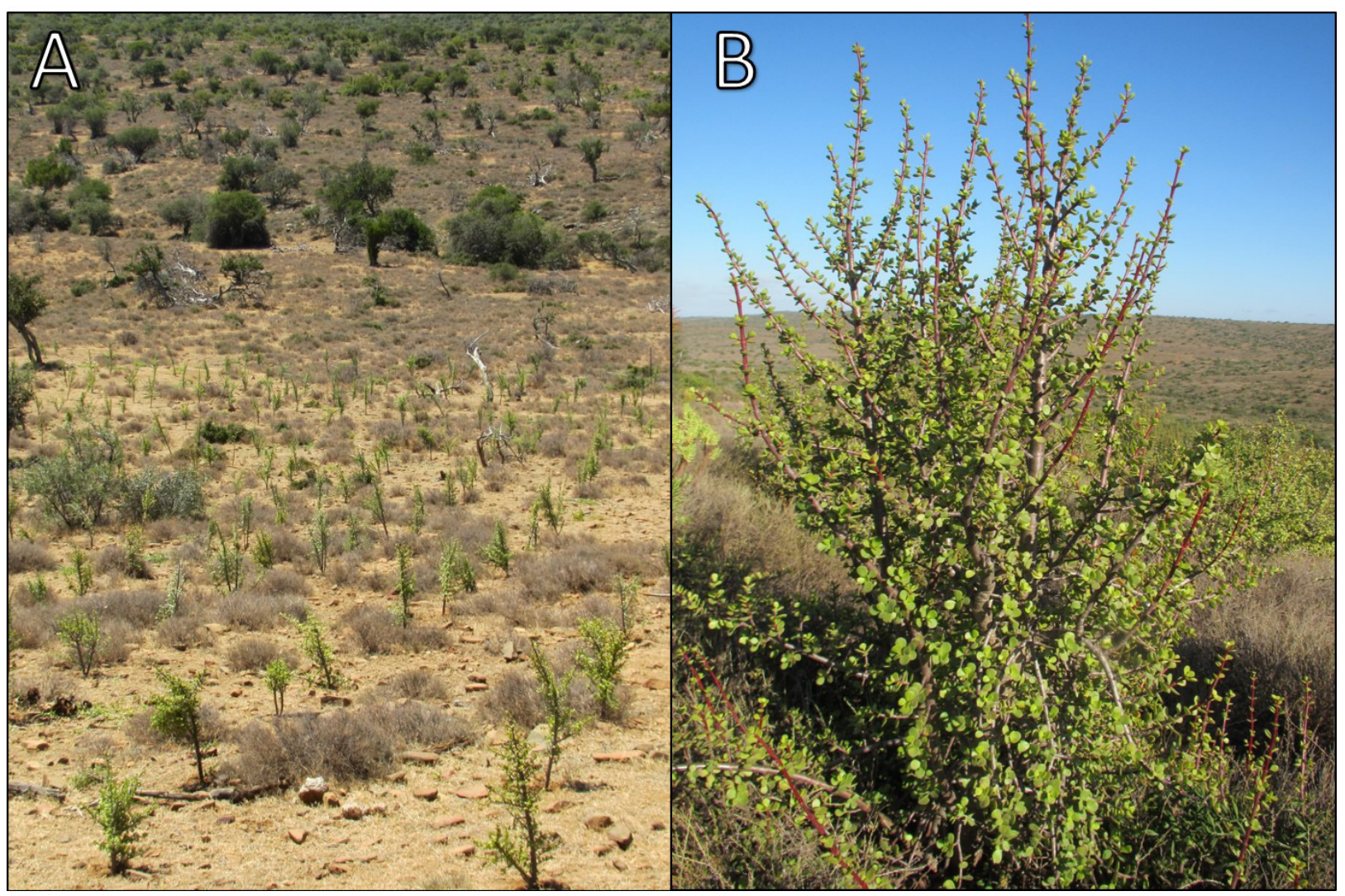

Figure 3. Spekboom cuttings planted into degraded thicket. (A) Newly planted cuttings; (B) A well-established cutting that has grown for several years subsequent to planting.

\subsection{The Assumption of Multiple Co-Benefits from Restoration Underpinned the STRP}

Although Mr. Slater had initially only planted his degraded thicket hillslope to stop flooding and to increase the availability of fodder, the STRP leadership worked with the assumption that the type of restoration undertaken on Krompoort upscaled over thousands of hectares would generate numerous other benefits such as greater ecosystem productivity, increased biodiversity, reduced soil erosion, improved base flow of rivers, reduced sedimentation rates of dams and sequestration of carbon. In 2003, a small amount of funding ( US\$ 6,000) was provided by government and an NGO to investigate the rate of carbon sequestration from restoration on Krompoort. The results of this research showed that the rate of carbon sequestration through the growth of spekboom cuttings had been exceptional for a semi-arid region (up to $\sim 15 \mathrm{t} \mathrm{CO}_{2}$ per hectare per year over a 27-year period) [25]. Although Krompoort was only one site, the proof of concept that restoration was possible and that large amounts of carbon could be sequestered in the process (which could potentially be sold on international carbon markets) was sufficient evidence for the government to establish the STRP. 


\subsection{STRP Strategy}

Strategic decisions taken by STRP stakeholders were influenced by various institutional factors listed in Table 1. This institutional context resulted in the following decisions being taken by the STRP in 2004 [19]: (i) science was to form the platform for the programme, providing credible information to catalyse investment; (ii) managers, scientists and policymakers were to meet quarterly to adjust the programme where required; (iii) the main deliverable for the scientists in the programme was production of credible information not only in the peer-reviewed literature but also in the form of restoration protocols for practitioners to use; and (iv) verified carbon credits were to be generated for sale on the international carbon market. The STRP leadership also noted that peer-reviewed publications on ecosystem carbon stocks in degraded and intact thicket were critical for providing credible information to use for generating internationally accepted and verified carbon credits - a source of income which could potentially cover the costs of the large-scale restoration.

Table 1. Institutional factors influencing the strategic decisions of STRP stakeholders.

\begin{tabular}{|c|c|}
\hline No. & Factor \\
\hline 1 & $\begin{array}{l}\text { The involvement of government decision-makers-with backgrounds in economics and } \\
\text { ecology - who wanted science to guide the programme. }\end{array}$ \\
\hline 2 & $\begin{array}{l}\text { A scientific review of the extent of degradation in thicket (the STEP programme [27]) and the } \\
\text { subsequent lobbying for action by the South African National Biodiversity Institute. }\end{array}$ \\
\hline 3 & $\begin{array}{l}\text { Ecological research that was being undertaken on thicket degradation (e.g., the Global Environment } \\
\text { Facility project - Conservation of globally significant biodiversity in agricultural landscapes in South } \\
\text { Africa through Conservation Farming). }\end{array}$ \\
\hline 4 & Availability of ecological data on fence-line contrasts between degraded and intact thicket $[28,29]$. \\
\hline 5 & $\begin{array}{l}\text { Experience of government decision-makers in establishing the Fynbos Forum-a network of } \\
\text { landowners, practitioners and scientists. }\end{array}$ \\
\hline 6 & $\begin{array}{l}\text { The norm at the time in South Africa of soliciting expert scientific advice when implementing } \\
\text { environmental projects. }\end{array}$ \\
\hline 7 & $\begin{array}{l}\text { The leeway afforded scientists by virtue of their numerical dominance at STRP meetings, especially } \\
\text { the inception meeting. }\end{array}$ \\
\hline 8 & A large emphasis placed by government decision-makers on publishing peer-reviewed papers. \\
\hline 9 & $\begin{array}{l}\text { The enthusiasm for international carbon markets at the time (the Clean Development Mechanism had } \\
\text { just been established) and the desire to be at the forefront of this new global carbon credit industry. }\end{array}$ \\
\hline
\end{tabular}

\subsection{STRP Ventures and Gains}

Over the past decade, the STRP has created a sizeable knowledge base on the restoration of spekboom thicket (S1), with a strong focus on carbon sequestration, and has established a large-scale experiment of different restoration protocols. To the best of our knowledge this experiment is the largest ecological restoration experiment in the world. The programme has also planted out more than 10,000 ha of degraded thicket with spekboom cuttings at a density of 2500 cuttings per hectare. The total cost of the science and the restoration over the past five years has been $\sim$ US\$8 million (based on a 2014 dollar value), sourced predominantly from the South African government's EPWP (which has a primary focus on job creation in rural areas). 
The rate of planting - using both public and private sector funds - over the past three years is approximately 2000 hectare per year. Data collected recently in Addo Elephant National Park show that average survivorship of cuttings ranged from 0 to $\sim 80 \%$ depending on factors such as season of planting and density of elephants (Loxodonta africana: Blumenbach, 1797) in the restoration area (unpublished data). Importantly, the cost of restoration has decreased considerably over the ten years of implementation, from approximately US\$3000 to approximately US\$300 per hectare, as various methods of restoration have been developed and tested [30]. This decrease in cost is largely a result of changing the restoration methodology from manual digging of holes using picks to using petrol-powered augers. In terms of carbon sequestration: 4.7 million ex-ante carbon credits - using a carbon sequestration rate of 80 tonnes $\mathrm{CO}_{2} \mathrm{e} /$ hectare [31] — have been generated through the validation of two projects (one in the public sector and one in the private sector) under the Verified Carbon Standard (VCS) and Climate Conservation and Biodiversity Alliance (CCBA). These credits have yet to be sold but there is cautious optimism that relatively high prices ( $>\$ 10$ per tonne of carbon dioxide) will be achieved because of the impending introduction of a carbon tax in South Africa [32] which is likely to allow for some carbon offsetting using VCS/CCBA carbon credits.

\subsection{What Further Sleeve-Rolling Is Required?}

Although there has been a lot of progress in the past decade, the current rate of restoration is modest given that more than a million hectares need restoration [31]. Notwithstanding the fact that not all degraded thicket should or could ultimately be restored to dense thicket, the rate of restoration needs to increase by a factor of fifty if meaningful progress towards restoring degraded thicket across the Eastern Cape is to be made over the next decade. For this major transformation in land use practice to occur, there will need to be a considerable shift in some aspect of the programme. The pressing questions facing the STRP are: "where is the game-changer for increasing the rate of restoration by more than an order of magnitude going to come from?"; "how will science inform the restoration protocols?" and "how will landowners be motivated and/or incentivized to restore their degraded subtropical thicket?" With these questions in mind, the STRP leadership has recently reflected on the last decade of experiences to develop a strategy for the next decade.

\subsection{Transforming the Science from a Static Platform into a Dynamic Scaffolding}

At the outset of the STRP, scientific research was viewed as a platform upon which the programme would develop. Researchers were going to generate, for example, information on restoration protocols for maximising biodiversity versus carbon sequestration [19]. The main step taken in this direction was to establish a large-scale restoration experiment - 331 quarter-hectare, fenced plots with 12 different treatments (including inter alia different size and spacing of cuttings) in a randomized design-over an area of $\sim 75,000 \mathrm{~km}^{2}$ across the thicket biome (Figure 4). This experiment took a decade to plan, implement and generate results for analysis. In the interim, a restoration protocol was adopted — without intensive, continual scrutiny of its efficacy - for implementation across more than ten thousand hectares. This protocol for the large-scale roll-out of restoration entailed planting — without careful consideration of position within the landscape - spekboom cuttings of $\sim 20 \mathrm{~mm}$ diameter (at the base of the cutting) to a depth of 15-20 cm vertically in the soil at a density of 2500 cuttings per hectare. 


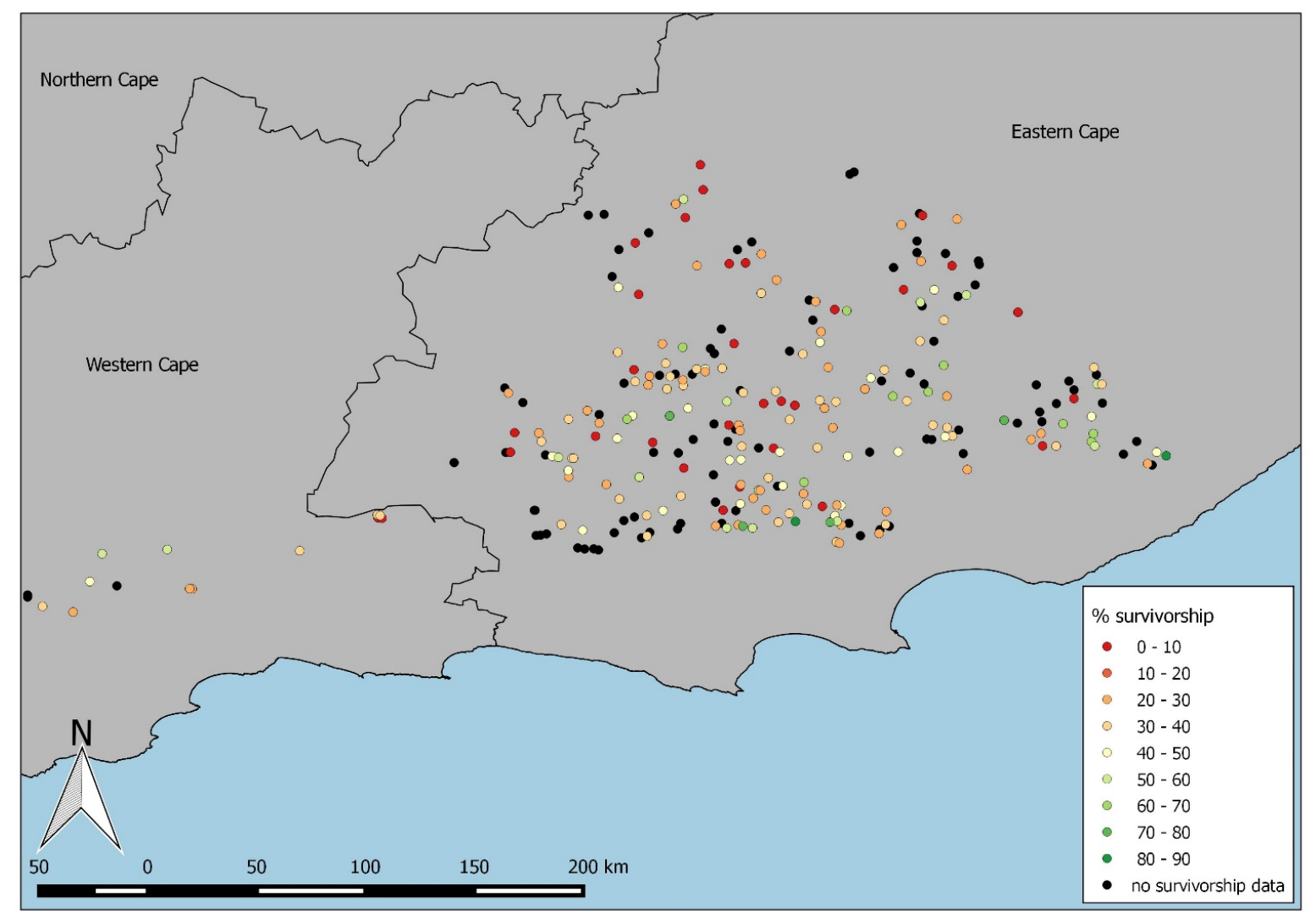

Figure 4. Location of the 331 plots within the large-scale restoration experiment conducted by the STRP in the Eastern Cape and Western Cape, South Africa. Different colours of circles denote average survivorship across all treatments in individual plots.

A major shortcoming of the STRP was that despite conducting considerable amounts of research $[24,25,33,34]$ an adaptive management approach $[35,36]$ of regularly refining the protocol for the large-scale roll-out of restoration was not adopted. For example, the effect of landscape position on survivorship of spekboom cuttings in the roll-out was not rigorously analysed. Furthermore, the economics of restoration, particularly the wide range of potential income streams (e.g., venison, mohair, goat meat, honey) were not quantified for the first decade of the STRP. Accurate cost-benefit analyses of restoration - the results of which would be of fundamental importance for would-be investors - could not, therefore, be undertaken. The resultant uncertainty around efficacy of restoration protocols in different landscapes and the returns on investment led to private sector investors shying away from large-scale restoration projects.

In short, the large investment in a well-replicated, large-scale experiment resulted in a relative scientific stasis in the STRP, with a notable absence of additional experiments, revisions to the adopted protocol and other activities consistent with an adaptive management approach [35,36]. This was primarily because stakeholders were patiently waiting for results to emerge from the large-scale experiment which was perceived to be the main scientific platform of the programme. Related insights gained which emerged during STRP operations, and which are potentially relevant for bridging the science-practice divide and catalysing private sector investment in large-scale restoration, are detailed in Section 2 below. These insights were collated after discussion and debate with a wide range of stakeholders involved in the STRP. Twelve insights — which are likely to be relevant to a wide range of 
restoration programmes - are presented, covering the following themes: implementation of large-scale experiments (Sections 2.1 to 2.3 below); programme management (Sections 2.4 to 2.7); private sector operations (Sections 2.8 to 2.10); and prescribing innovation (Sections 2.11 and 2.12). The main implications for practice that follow on from these insights are summarized in section 4's "Concluding recommendations".

\section{Insights Gained}

\subsection{Effective Implementation of Large-Scale Experiments Requires Intensive Scientific Oversight in the Field}

The three managers tasked with implementing the STRP's large-scale experiment, with a work force of approximately 100 unskilled labourers, were trained by vegetation ecologists to select sites for the location of each plot in degraded thicket (which had previously had spekboom as a dominant species). They were also trained on the importance of using a randomized design for subsequent statistical analysis of the data. Unfortunately the training was not sufficient to ensure effective implementation of the experiment especially in terms of site selection and record-keeping. This was evident in that: (i) steep, rocky sites - despite being most appropriate for plot locations - were often avoided to make planting operations easier to undertake; (ii) insufficient record-keeping during the planting operation prevented accurate identification of all treatments in 50\% of sites; (iii) considerable mortality of cuttings occurred - ostensibly as a result of frost - in plots that had been established inappropriately in bottomlands; (iv) certain teams of labourers were more fastidious than others in implementing the experimental treatments (unpublished data); and (v) livestock were found to have entered certain plots where fences had been poorly maintained.

In hindsight, a trained vegetation ecologist should have visited each site during the planting operations to ensure that appropriate vegetation types were being chosen for the location of each plot, that the order of treatments in each plot was being rigorously documented, and that the instructions for implementing the 12 different experimental treatments were being carefully followed. More frequent interactions with landowners, to get their support on long-term maintenance of fences, would also have been beneficial.

\subsection{A Large Number of Replicates Can Provide a Counter-Balance for the Difficulties of Ensuring Rigorous Implementation of Restoration Experiments}

The STRP's large-scale experiment was designed to enable a statistical analysis using a boundary line approach [37-40]. Because this approach requires a large numbers of replicates, more than 300 plots were established. Approximately half of these plots were compromised to some extent by ineffective implementation or livestock entering the plot (see Section 2.1 above). However, the remaining $\sim 150$ plots provided a sufficient sample size for yielding many valuable insights from the experiment. For example, at the outset of the experiment it was anticipated that the survivorship of large cuttings ( $\sim 25 \mathrm{~mm}$ stem diameter) would be several times greater than that of small cuttings $(\sim 10 \mathrm{~mm})$. A preliminary analysis of the data from the experiment indicates, however, that the average survivorship of small cuttings, in certain environments, can be considerable even rivalling that of large cuttings (unpublished data). A finding such as this has the potential to greatly reduce the cost of future restoration 
initiatives because small cuttings are considerably easier to harvest and plant. It has also emerged, from preliminary analysis, that the topographical position of the planting has considerable bearing on the survivorship of cuttings.

\subsection{The Ramifications of a Large-Scale Experiment Taking a Decade to Yield Results Need to be Fully Considered}

Despite the STRP's large-scale experiment yielding valuable insights, it took a decade for these insights to emerge. The "intelligent tinkering" approach, advocated by authors such Cabin, 2008 [40], Cabin, 2009 [41] and Murcina and Aronson, 2014 [42] is likely to fast-track the learning process. Such tinkering ranges from small-scale, rapid assessments [42] to large-scale, long-term experiments [43] and enables restoration practitioners to develop a wide range of protocols for different environmental conditions. This is invariably necessary because there are inevitably too many important environmental variables (e.g., soil chemical/physical properties, topography, climate) to investigate using well-replicated, large-scale experiments.

\subsection{Funder's Objectives Need to Be Well-Aligned with Restoration Outcomes}

The funding of the STRP was predominantly via the South African government's EPWP-a programme which focuses on poverty alleviation in rural areas. Given the funder's overarching agenda, the main implementing agents within the STRP needed to minimise management overheads such as scientific oversight while maximising job creation. Notably, the success of the restoration process was not specifically incorporated into the implementing agents' terms of reference. As a result, minimal data was collected on survivorship of spekboom cuttings in the STRP's large-scale roll-out. Furthermore, incentive structures within the STRP did not motivate managers or labourers to undertake planting practices that resulted in successful establishment of spekboom cuttings because remuneration was based simply on planting of cuttings in sufficient densities over a specified time period. A side effect of the scarcity of survivorship data was that the main restoration protocol adopted by the STRP continued to be used despite numerous anecdotal reports that survivorship of cuttings was poor in certain landscapes (e.g., in frost-prone bottomlands).

\subsection{Continual Scrutiny and Reassessment of Assumptions Underpinning Selection of Particular} Restoration Protocols is Required

The STRP selected a restoration protocol for large-scale roll-out based on the apparent evidence from the farm, Krompoort, that survivorship of planted cuttings would be close to $100 \%$ even in severe droughts. It was acknowledged within the STRP that survivorship would vary across different environments; however, Mr Slater's experience at Krompoort suggested that the protocol was likely to be effective. In retrospect, there was insufficient scrutiny of the protocol used at Krompoort versus the protocol adopted by the STRP. For example, at Krompoort, the restoration was conducted by labourers who were skilled in digging deep holes for fence poles, and who were overseen by a farmer greatly motivated to see his degraded thicket restored successfully. Relatively wide and deep holes were dug with sharp iron bars, and the spekboom cuttings were planted into loose soil. By contrast, in the STRP, 
a planting protocol developed whereby: (i) spekboom cuttings are planted into relatively narrow and shallow holes drilled by petrol-powered augers; and (ii) iron bars are often used to open the narrow holes by forcing loose soil to the bottom of the holes. This often results in soil at the bottom of the narrow hole being compacted rather than loosened. It is not known to what extent the compacting of soil, the relative paucity of loose soil, the narrowness of the hole, and/or the relatively shallow depth of planting affects survivorship of spekboom cuttings. What is evident, however, is that there has been a considerable departure from the original method used at Krompoort in terms of both the planting protocol and psychology of management. Preliminary results from the STRP's large-scale experiment and roll-out suggest that relatively shallow planting has resulted in considerable mortality because numerous cuttings have been encountered lying horizontally on the ground, as opposed to firmly planted in a vertical position. There is also evidence indicating that survivorship of cuttings is, at most sites, considerably less than what was ostensibly achieved at Krompoort. This applies to plantings undertaken within public as well as private sector operations (Figures 5 and 6).
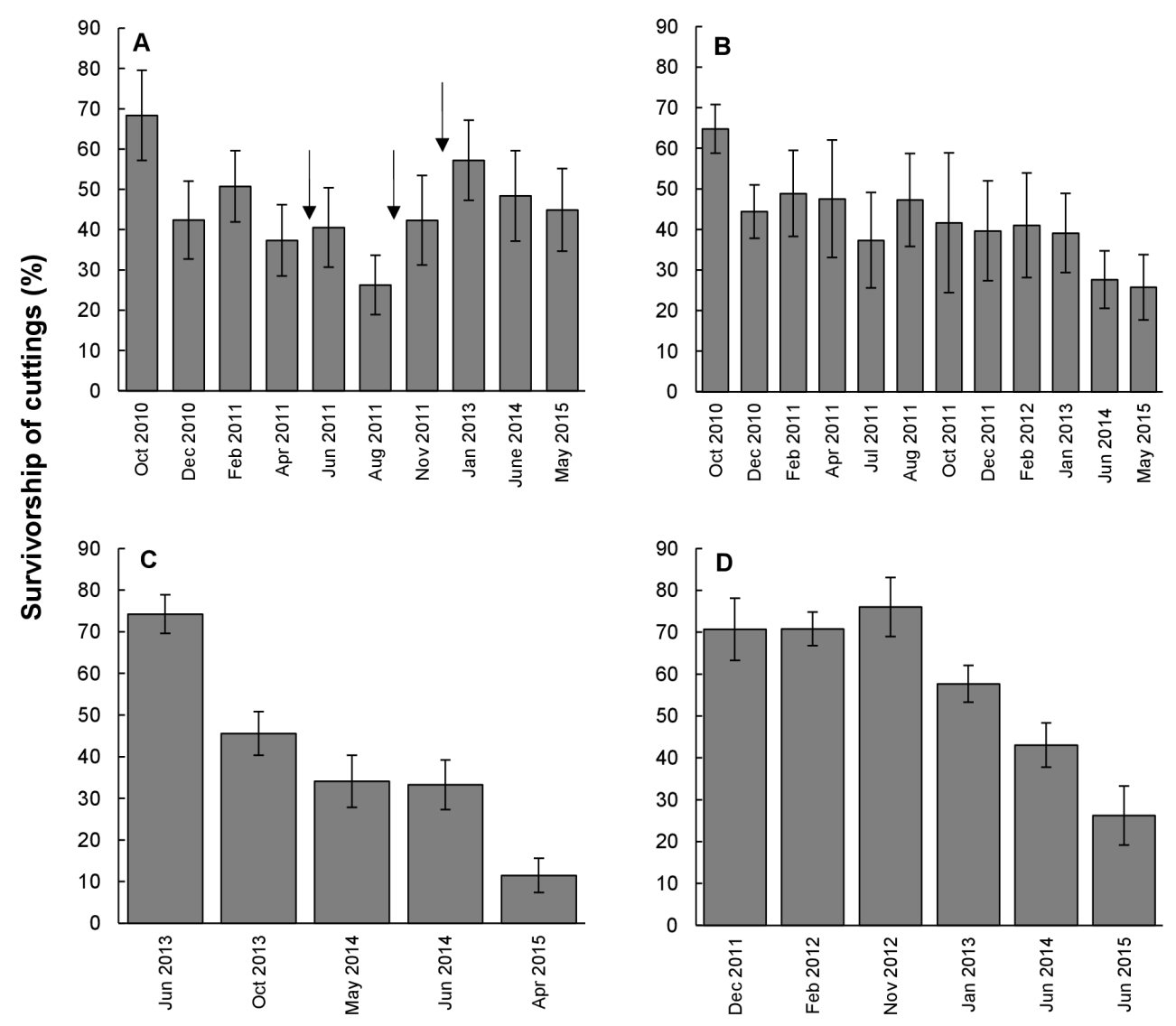

Monitoring date

Figure 5. Percentage survivorship ( \pm standard error) of spekboom cuttings ( $20 \mathrm{~mm}$ basal diameter at planting) planted at sites in the Eastern Cape, South Africa. (A) 50 hectare of plantings $\sim 40 \mathrm{~km}$ SE of Steytlerville; (B) 50 hectare of plantings $\sim 30 \mathrm{~km} \mathrm{NW}$ of Jansenville; (C) 110 hectare of plantings $\sim 65 \mathrm{~km} \mathrm{SE}$ of Graaff-Reinet; (D) 104 hectare of plantings $\sim 70 \mathrm{~km} \mathrm{~W}$ of Riebeek East. All sites were planted at an initial density of 2600 to 5000 cuttings per hectare. Data were recorded in 2015 from $10 \mathrm{~m} \times 10 \mathrm{~m}$ plots and the number of plots sampled in each site varied from 5 to 15 . Arrows indicate events of supplementary planting. 


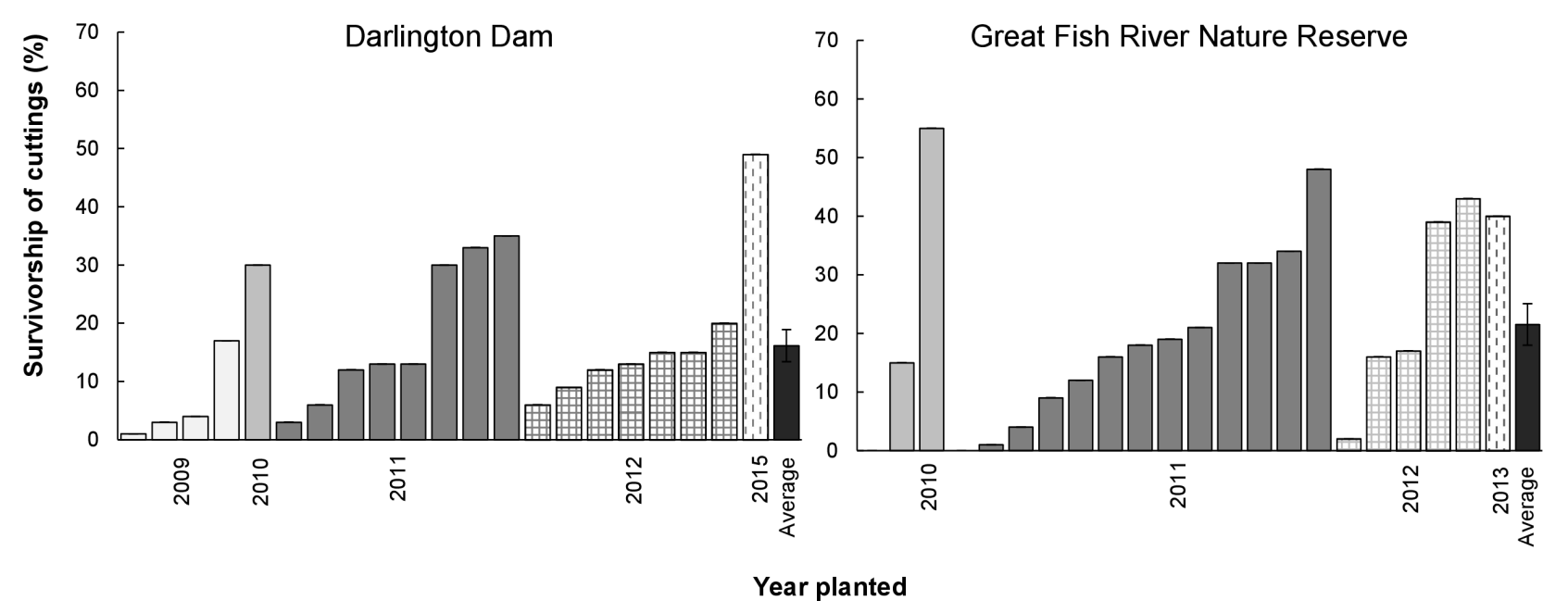

Figure 6. Percentage survivorship of spekboom cuttings planted in different years at sites in the Eastern Cape, South Africa. Darlington Dam (within the Addo Elephant National Park) is $\sim 85 \mathrm{~km} \mathrm{SE}$ of Jansenville. Great Fish River Nature Reserve is $\sim 85 \mathrm{~km} \mathrm{NE}$ of Grahamstown. Both sites were planted at a density of 2500 cuttings per hectare. Survivorship data were recorded in 2015 from 21 plots $(20 \mathrm{~m}$ by $20 \mathrm{~m}$ ). Average percentage survivorships (+ standard error) in Darlington Dam and Great Fish River Nature Reserve, respectively, are indicated by solid black bars.

\subsection{A Counter-Balance for the Planning Fallacy is Necessary}

Public and private sector operations within the STRP often succumbed to the "planning fallacy", i.e., the tendency to underestimate the time, costs, and risks of future actions and at the same time overestimate the benefits of the same actions [44,45]. Examples of STRP operations that were at times compromised by the planning fallacy included: (i) restoration roll-outs over large areas; (ii) monitoring the restoration in a rigorous manner; (iii) publishing the results in the peer-reviewed literature; and (iv) timeous releasing of funds from government. One potential way of avoiding the planning fallacy is to contract third party entities to provide a reality-check on estimated costs and timeframes. Research has shown that third party entities tend to overestimate costs and time requirements, which could provide a useful balance to the bias of optimism by stakeholders within a particular programme or business [46].

\subsection{Ecologists Tend to Be Ill-Equipped for Providing Technical Guidance on Restoration Operations}

The STRP faced typical challenges of the knowledge-action boundary [12,47] and in retrospect did not have sufficiently close collaboration between scientists and managers [47] despite quarterly meetings. Project managers implementing the planting of spekboom required technical guidance on matters such as how to (i) innovate with new equipment; (ii) develop management systems for ensuring that all planting is done to specified standards (e.g., size of plant, depth of holes); (iii) reduce the time taken for all tasks; and (iv) incentivize staff effectively. Skills in agronomy, horticulture and management — as opposed to ecology — are typically required to provide this guidance. However, ecologists were frequently tasked, particularly within private sector operations, to fulfil this technical 
role. As a result, the efficiencies of many operations were compromised. In hindsight, the STRP would have benefited from training all scientists - who were visiting the field regularly - to analyse the efficiency of the management of the restoration operations, rather than advising solely on ecological processes. Also, agronomists, horticulturalists, soil scientists and ecologists should have ideally conducted joint field visits. Furthermore, frequent collaboration - via on-the-ground discussions and site visits - between scientists and project managers would have assisted in: (i) appropriate site selection; (ii) maintenance of planting standards; and (iii) quality control of data collection and archiving procedures. For this to have occurred, it would also have been necessary to provide clear terms of references for the scientists as well as budget allocations for these visits. Discrete tasks and deliverables (e.g., detailed field visit reports on a wide range of management and ecological topics), with associated timelines and penalties, would need to have been specified and budgeted for accordingly.

\subsection{Private Sector Operations Require a Greater Focus on Reducing Costs, Exposing Failure and} Innovating than Government-Funded Programmes

Flexibility and rapid innovation that reduces costs and exposes failures tend to underpin the operations of small businesses [48-50]. As Amara et al., 2008 [51] note: "For many firms, the challenge is ... about increasing the degree of novelty of their innovations in order to improve their competitive advantage". By contrast, government ministries, parastatal organizations and university departments [52] tend to change their paradigms and modus operandi in a methodical, systematic and slow manner. It is consequently difficult for a large government programme to guide the establishment of small businesses. In particular, small businesses need to identify, expose and manage failures decisively. By contrast, governments and universities understandably tread more gently around failures. As a senior government stakeholder within the STRP noted: "The danger with exposing failure in any part of the system is that individuals involved become threatened. The secret to the successful implementation of a feedback system is not to make people feel incompetent but to stick to the facts around the issue. This is easier said than done..."

\subsection{Private Sector Start-Ups in Pioneering Restoration Industries will Invariably Face}

\section{Considerable Pitfalls}

The private sector encompasses a wide range of entities from single entrepreneurs (with novel ideas but minimal experience in running businesses and setting up systems of management) to large corporations (with sophisticated systems of management which create economies of scale and which can handle the unexpected events that inevitably occur during the course of implementing an investment). During the course of the STRP, numerous small private sector businesses developed on the periphery of the programme. This was a successful outcome in that it was part of the STRPs overarching mandate, namely catalysing private sector involvement in thicket restoration. Particularly noteworthy small businesses that emerged were teams of labourers that subcontracted their services to government as well as private sector restoration projects. Each team comprised approximately 10 to 12 labourers, and over the course of the STRP, more than a hundred teams were subcontracted. Institutional arrangements with the STRP did not, however, guarantee regular income for these teams and consequently their financial sustainability was frequently jeopardized. 
Project development businesses were another type of private sector operation that emerged from the STRP. An implicit assumption within the STRP at the outset was that such businesses would be efficient and effective, and that uptake by the private sector would be the solution for raising finance for large-scale restoration across the thicket biome. What emerged, however, is that project development businesses in a pioneering industry tend to have considerable weaknesses. These included insufficient skills and managerial capacity for reducing gross inefficiencies in the planting operations (e.g., lack of functioning digging equipment) and for innovating to develop new protocols (e.g., for managing hard soils or tracking size of spekboom cuttings being harvested).

In hindsight, project development businesses within the STRP would have benefited from intensive training on: (i) developing a mindset of entrepreneurship/innovation (see Section 2.11 below; (ii) conducting field trips that focused on the honing of restoration protocols and management systems; (iii) collecting rigorous data (e.g., time-motion studies used to assess the methodological efficiencies/inefficiencies in planting protocols, survivorship, growth) to quantify weaknesses within on-the-ground operations; and (iv) developing and implementing protocols for decision-making, communication, long-term strategizing, marketing, and resolution of conflicts within the businesses.

\subsection{Formal Mechanisms for the Exchange of Knowledge between Public-Funded Entities and Private Sector Need to Be Established}

Project development businesses were largely unable to capitalize on the experiences of the STRP implementing agents - particularly in terms of reducing the costs of implementation - because formal channels of exchanging knowledge on management systems were not in place. Indeed, institutional arrangements within the STRP often had the unintended side effect of blocking the exchange of knowledge between these businesses and implementing agents. As a result, (i) private sector projects started with high costs (comparable to the costs the government implementing agent experienced at the start of the STRP) because management systems were created from scratch; and (ii) the need for honing managing systems was greatly underestimated by the private sector stakeholders.

\subsection{A Strong Ethos of Debate Amongst all Stakeholders Is Imperative for Innovation in}

\section{Restoration Initiatives}

The application-without scrutiny and testing — of one protocol for the large-scale roll-out of restoration resulted in several negative effects within the STRP, including (i) considerable mortality of spekboom cuttings in certain landscapes; (ii) the halting of private sector projects so that new, cost-effective protocols could be developed for a range of soil types; (iii) the inability of private sector project developers to produce accurate financial models for a range of landscapes; and (iv) on occasion, conflict among STRP stakeholders in terms of how to manage and adjust restoration protocols. On the last point, it should be noted that innovation is well-known to emerge from well-managed conflict in most disciplines, including the natural sciences [53]. As the renowned business management expert, Peter F. Drucker noted: "Decisions of the kind the executive has to make are not made well by acclamation. They are made well only if based on the clash of conflicting views, the dialogue between different points of view, the choice between different judgements. The first rule in decision-making is that one does not make a decision unless there is disagreement" [54]. 
In hindsight, private sector stakeholders in particular needed a neutral platform within the STRP for debating and challenging any entrenched views on restoration protocols to ensure that the most cost-effective protocols emerged. For example, instead of accepting that large-scale restoration should be undertaken solely using the restoration protocol entrenched within the STRP operations, the cost-effectiveness of planting small cuttings and drilling holes with a wide range of technologies (e.g., jackhammers as opposed to augers) should have been quantified rigorously and debated intensely.

\subsection{Intelligent Tinkering Needs to be Prescribed, Not Assumed}

At the outset of the STRP there was a spoken-but not documented-assumption amongst stakeholders that to catalyse investment in restoration, considerable innovation would be required to: (i) reduce the costs of restoration; (ii) maximize survivorship and growth of cuttings; (iii) quantify potential income streams from restored landscapes; and (iv) establish bridging finance mechanisms for project developers and landowners. Deliverables from the programme's main stakeholders - implementing agencies and ecologists - were not, however, tailored to ensure that this specific type of innovation was undertaken. Stakeholders were given considerable scope to undertake the work as they deemed fit. As a result there was a tendency for both implementing agents and ecologists to gravitate towards their comfort zones of "business as usual", including documenting the number of jobs created (in the case of the implementing agencies) and publishing on ecological processes (in the case of the ecologists). Horticultural research, complex economic analyses, structuring of financial mechanisms, and data collection on success of plantings were given only minor, if any, attention. This experience has led STRP management to reach the following conclusions: (i) within the STRP, innovation on specific topics should have been assigned to specific institutions and contracted individuals, with the results of their work being publically available; (ii) appropriate incentive structures for the institutions and individuals tasked with innovation needed to be carefully developed; and (iii) penalties for these institutions and individuals should have been imposed only if there was failure to attempt innovation in a rigorous manner, not if there was failure to make a breakthrough and develop a successful restoration protocol or financial model.

\section{Towards a Tipping Point}

Ten years on, STRP stakeholders still hold the view that if degraded thicket is to be restored at a biome-scale over the next few decades, a new restoration industry underpinned by private sector investment (from landowners and investors) will need to develop. This implies the advent of a restoration economy, i.e., the development of a restoration industry funded by, largely, the private sector. Economists and scientists working on forest restoration initiatives in Sao Paulo state, Brazil, have reached similar conclusions [55]. The assumption underpinning the STRP's approach is that a degraded thicket landscape that has been successfully restored through the planting of spekboom cuttings can generate, in time, sizeable profits for landowners. The STRP's working hypothesis is that by reducing the costs of restoration and increasing the predictability, as well as size, of income streams derived from restored landscapes, a tipping point will be reached during the next decade in which the private sector will join the public sector in investing in large-scale restoration. Several large corporates in South Africa have indicated their willingness to participate in such private-public partnerships, using corporate social 
responsibility budgets initially but with the long-term goal of producing carbon credits and generating new income streams (e.g., from venison or wildlife sales) from restored thicket. Furthermore, several private sector initiatives have started experiments with a wide range of new restoration protocols.

The STRP's approach differs from initiatives such as the Atlantic Forest Restoration Pact where legislation obliges landowners to restore a certain percentage of their land. The South African government, at this point, in time does not envisage legislating restoration of thicket because (i) the costs are likely to be beyond the means of many landowners (the returns from farming in degraded thicket landscapes are relatively small); (ii) there is a delay of five to ten years between the planting of cuttings and potential benefits from improved income streams; and (iii) the restoration protocols are not fully tried and tested.

In terms of reducing costs of implementation, promising avenues of research being explored by private sector initiatives include: (i) developing tailor-made equipment for drilling holes rapidly in hard soils; (ii) planting small as opposed to large cuttings; (iii) removing the cost of digging holes by placing cuttings of different sizes (rooted within a soil mass or non-rooted) horizontally on the soil surface (thereby simulating the natural ecological process of African elephant and black rhinoceros (Diceros bicornis: Linnaeus, 1758) knocking off branches which propagate on the soil surface); (iv) determining - based on the STRP large-scale experiment results - the environmental conditions that result in good survivorship (e.g., >70\%) of all treatments; and (v) reducing the damage to cuttings from frost and browsing by using existing perennial shrubs as nursery/cover plants for the cuttings. All of these options need methodical testing using an intelligent tinkering approach [42].

An important income stream requiring quantification is the production of game and livestock in restored thicket. Agricultural research suggests that restored thicket landscapes are likely to be several times more productive in terms of animal production than degraded landscapes [20]; however, research is necessary to determine appropriate herbivore stocking rates for restored thicket. Potential income streams include venison, mohair and goat meat but also conservation and breeding of endangered wildlife species. Subtropical thicket is, for example, prime habitat for African elephant and black rhinoceros [56] - an ecological facet which in time could be a major competitive advantage for restoration practitioners wanting to raise finance for restoration of degraded thicket. It is not practical to undertake research on game and livestock over large areas of fully restored thicket because such landscapes do not exist. Consequently, some of this research—like the research on carbon stocks_may need to rely on the fortuitous restoration trials undertaken several decades ago by private landowners [25], as well as on modelling.

Social science research is also required to understand what would incentivize a landowner to set aside land for the restoration process. Financial returns alone may not be sufficient motivation for some landowners to change their land use practices. This is because many of the farms in the Eastern Cape have been owned by one family for several generations, and particular land use practices are consequently deeply embedded in the farming culture of the region. What is evident is that appropriate legislation and institutional arrangements for facilitating restoration and maintenance of thicket by different land users are likely to differ considerably across the Eastern Cape. For example, restoration of communally owned land will require different institutional arrangements compared with privately owned land. Notwithstanding the social complexities in different parts of the landscape, there are likely 
to be common requirements for catalysing thicket restoration across all geographic locations, such as increasing economies of scale and reducing transaction costs.

Financial models that capture a wide range of income streams from restored thicket, over timeframes of several decades, will need to be developed. And appropriate marketing of the models - using, for example, the concept of "restoring natural capital" [42,57]—will need to take place to raise the finance. Both of these steps will require the expertise of finance and marketing experts. Mechanisms for providing bridging finance such as environmental bonds, public-private partnerships or concessional loans will, in all likelihood, also need to be established in order to (i) provide finance for the implementation of the restoration; (ii) reduce the risk for the private sector [58,59]; and (iii) cover the potential loss of farming income during the restoration process. At present, private sector investors are only likely to invest in restoration of degraded thicket if public sector funds are used to considerably reduce the risks involved. A potential mechanism for reducing risks for the private sector is the use of public sector funds to guarantee the purchase of products produced from restored landscapes (e.g., carbon credits, water purification, reduced soil erosion, enhanced biodiversity, mohair, goat meat and venison). Such guarantees could, for example, incentivize environmental impact investors to invest in instruments such as environmental impact bonds. Tax rebates for land owners undertaking effective restoration are yet another potential mechanism for incentivizing the private sector to invest in restoration of degraded thicket.

\section{Concluding Recommendations}

Based on the experiences in the STRP's first decade, new, large-scale restoration programmes should seek to avoid three main pitfalls. Firstly, institutions tasked with implementing large-scale restoration will often be incentivized to entrench a particular restoration protocol into their operations before the efficacy of the protocol has been thoroughly analysed. Such entrenchment should be resisted. Secondly, large-scale restoration in many degraded environments will require the involvement of inexperienced, private sector businesses. These businesses will invariably require intensive training on developing management systems to reduce inefficiencies. Thirdly, the private sector, government and academia will often have different agendas and requirements regarding the development of cost-effective restoration protocols. Government and academia will, for example, tend to innovate more slowly than is required by small businesses. To address this mismatch in needs, and to catalyse investment by the private sector, government-funded restoration programmes should inculcate an ethos of continual enquiry into their operations. Trial and error should be the order of every day for managers and scientists alike in such programmes.

In retrospect, it is evident that the science within the STRP became separated from both the implementation and economic analysis of the large-scale restoration operations. What the STRP needed was a dynamic scientific scaffolding that grew with the experiences of the implementing agents, as opposed to a static scientific platform in the form of a single large-scale experiment. To construct such a scaffolding, scientists and managers should have been assigned — at the outset of the STRP - the responsibility of refining a wide range of restoration protocols in an iterative manner through numerous well-documented, small experiments in addition to the well-replicated, large-scale experiment. Such "intelligent tinkering" [42] should also have been used to quantify potential income streams from 
the restored landscapes. As the STRP enters its second decade, a new approach of embedding innovation - as opposed to entrenched protocols - into its day-to-day operations is being adopted.

\section{Acknowledgments}

We thank Richard Cowling for valuable discussions on earlier versions of the manuscript, and Bentley Kaplan, Leigh-Ann de Wet and Stephan Coetzee for assisting with the preparation of the final manuscript. We gratefully acknowledge the South African Government's Department of Environmental Affairs, Natural Resources Management Programme (grant number FA2005040700027) for funding this research.

\section{Author Contributions}

Anthony Mills wrote most of the text in the manuscript. All other authors contributed by providing valuable comments and actively debating many of the points presented.

\section{Conflicts of Interest}

The authors declare no conflict of interest.

\section{References}

1. World Conservation Union. The Bonn challenge on forests, climate change and biodiversity, 2011. Available online: http://cmsdata.iucn.org/downloads/bonn_challenge_flyer_highres.pdf (accessed on 26 November 2014).

2. King, S.L.; Keeland, B.D. Evaluation of reforestation in the Lower Mississippi River Alluvial Valley. Restor. Ecol. 1999, 7, 348-359.

3. Pinto, S.R.; Melo, F.; Tabarelli, M.; Padovesi, A.; Mesquita, C.A.; Scaramuzza, C.A.; Castro, P.; Carrascosa, H.; Calmon, M.; Rodrigues, R.; et al. Governing and delivering a biome-wide restoration initiative: The case of Atlantic Forest Restoration Pact in Brazil. Forests 2014, 5, 2212-2229.

4. Joly, C.A.; Metzger, J.P.; Tabarelli, M. Experiences from the Brazilian Atlantic Forest: Ecological findings and conservation initiatives. New Phytol. 2014, 204, 459-473.

5. Calmon, M.; Brancalion, P.H.S.; Paese, A.; Aronson, J.; Castro, P.; da Silva, S.C.; Rodrigues, R.R. Emerging threats and opportunities for large-scale ecological restoration in the Atlantic Forest of Brazil. Restor. Ecol. 2011, 19, 154-158.

6. Lü, Y.; Fu, B.; Feng, X.; Zeng, Y.; Liu, Y.; Chang, R.; Sun, G.; Wu, B. A policy-driven large scale ecological restoration: Quantifying ecosystem services changes in the Loess Plateau of China. PLOS ONE 2012, 7, e31782.

7. Barrow, E. 300,000 Hectares Restored in Shinyanga, Tanzania-But what did it really take to achieve this restoration? Surv. Perspect. Integr. Environ. Soc. 2014, 7, 1-8.

8. Brudvig, L.A. The restoration of biodiversity: Where has research been and where does it need to go? Am. J. Bot. 2011, 98, 549-558. 
9. Aronson, J.; Blignaut, J.N.; de Groot, R.S.; Clewell, A.; Lowry, P.P., II.; Woodworth, P.; Cowling, R.M.; Renison, D.; Farley, J.; Fontaine, C.; et al. The road to sustainability must bridge three great divides. Ann. N.Y. Acad. Sci. 2010, 1185, 225-236.

10. Dickens, S.J.M.; Sudig, K.N. Spanning the science-practice divide: Why restoration scientists need to be more involved with practice. Ecol. Restor. 2013, 31, 134-140.

11. Hampton, S.E.; Strasster, C.A.; Tewksbury, J.T. Growing pains for ecology in the twenty-first century. BioScience 2013, 63, 69-71.

12. Cook, C.N.; Mascia, M.B.; Schwartz, M.W.; Possingham, H.P.; Fuller, R.A. Achieving conservation science that bridges knowledge-action boundary. Conserv. Biol. 2013, 27, 669-678.

13. Gordon, I.J.; Evan, D.M.; Garner, T.W.J.; Katzner, T.; Gompper, M.E.; Altwegg, R.; Branch, T.A.; Johnson, J.A.; Pettorelli, N. Enhancing communication between conservation biologists and conservation practitioners: Letter from the conservation front line. Anim. Conserv. 2014, 17, 1-2.

14. Aronson, J.; Alexander, S. Ecosystem restoration is now a global priority: Time to roll up our sleeves. Restor. Ecol. 2013, 21, 293-296.

15. Menz, M.H.M.; Dixon, K.W.; Hobbes, R.J. Hurdles and opportunities for landscape-scale restoration. Ecology 2013, 339, 526-527.

16. LoSchiavo, A.L. Lessons learned from the first decade of adaptive management in comprehensive Everglades restoration. Ecol. Soc. 2013, 18, 70-85.

17. Salafsky, N.; Margoluis, R.; Redford, K. Adaptive Management: A Tool for Conservation Practitioners; Foundations of Success: Maryland, MD, USA, 2001.

18. Cabin, R.J.; Clewell, A.; Ingram, M.; McDonald, T.; Temperton, V. Bridging restoration science and practice: Results and analysis of a survey from the 2009 Society for Ecological Restoration International meeting. Restor. Ecol. 2010, 18, 783-788.

19. Mills, A.J.; Turpie, J.; Cowling, R.M.; Marais, C.; Kerley, G.I.H.; Lechmere,O.R.G.; Sigwela, A.M.; Powell, M. Assessing costs, benefits and feasibility of subtropical thicket restoration in the Eastern Cape, South Africa. In Restoring Natural Capital. Science, Business and Practice; Aronson, J., Milton, S.J., Eds.; Island Press: Washington, DC, USA, 2007; pp. 179-187.

20. Stuart-Hill, G.C.; Aucamp, A.J. Carrying capacity of the succulent valley bushveld of the Eastern Cape. Afr. J. Range Forage Sci. 1993, 10, 1-10.

21. Aucamp, A.J. The role of the browser in the bushveld of the Eastern Cape. Proc. Grassl. Sci. S. Afr. 1976, 11, 135-138.

22. Lloyd, J.W.; van den Berg, E.C.; Palmer, A.R. Patterns of Transformation and Degradation in the Thicket Biomes, South Africa; TERU Report No. 39; University of Port Elizabeth: Port Elizabeth, South Africa, 2002.

23. Hoffman, M.T.; Cowling, R.M. Desertification in the lower Sundays River Valley, South Africa. J. Arid Environ.1990, 19, 105-117.

24. Van der Vyver, M.L.; Cowling, R.M.; Mills, A.J.; Difford, M. Spontaneous return of biodiversity in restored subtropical thicket: Portulacaria afra as an ecosystem engineer. Restor. Ecol. 2013, 21, 736-744.

25. Mills, A.J.; Cowling, R.M. Rate of carbon sequestration at two thicket restoration sites in the Eastern Cape, South Africa. Restor. Ecol. 2006, 14, 38-49. 
26. Munang, R.; Thiaw, I.; Alverson, K.; Mumba, M.; Liu, J.; Rivington, M. Climate change and ecosystem-based adaptation: A new pragmatic approach to buffering climate change impacts. Environ. Sustain. 2013, 5, 67-71.

27. Biodiversity GIS. Subtropical Thicket Ecosystem Project 2003. Available online: bgis.sanbi.org/STEP/project.asp (accessed on 20 August 2015).

28. Todd, S.; Hoffman, M.T. A fence-line contrast reveals effects of heavy grazing on plant species diversity and community composition in a communally managed semi-arid shrubland, Namaqualand, South Africa. Plant Ecol. 1999, 142, 169-178.

29. Mills, A.J.; Fey, M.V. Transformation of thicket to savanna reduces soil quality in the Eastern Cape South Africa. Plant Soil 2004, 265, 153-163.

30. Department of Economic Development, Environmental Affairs and Tourism. Environmental programmes, Job Creation and Green Economy Cluster Meeting. Special Focus on Spekboom Biome. Port Elizabeth, 20 and 21 October 2014.

31. Mills, A.J.; Cowling, R.M.; Fey, M.V.; Kerley, G.I.H.; Lechmere, O.R.G.; Sigwela, A.; Skowno, A.; Rundel, P.W. Effects of goat pastoralism on ecosystem carbon storage in semi-arid thicket, Eastern Cape, South Africa. Aust. Ecol. 2005, 30, 807-813.

32. National Treasury. Republic of South Africa. Draft Carbon Tax Bill. Available online: http://www.treasury.gov.za/public\%20comments/default.aspx (accessed on 6 November 2015).

33. Van der Vyver, M.L.; Cowling, R.M.; Campbell, E.E.; Difford, M. Active restoration of woody canopy dominants in degraded South African semi-arid thicket is neither ecologically nor economically feasible. Appl. Veg. Sci. 2012, 15, 26-34.

34. Mills, A.J.; Cowling, R.M. How fast can carbon be sequestered when restoring degraded subtropical thicket? Restor. Ecol. 2014, 22, 571-573.

35. Armitage, D.R.; Plummer, R.; Berkes, F.; Arthur, R.I.; Charles, A.T.; Davidson-Hunt, I.; Diduck, A.P.; Doubleday, N.C.; Johnson, D.S.; Marschke, M.; et al. Adaptive co-management for social-ecological complexity. Front. Ecol. Environ. 2008, 7, 95-102.

36. Lee, K.N. Appraising adaptive management. Conserv. Ecol. 1999, 3, 3.

37. Walworth, J.L.; Summer, M.E. The diagnosis and recommendation integrated system (DRIS). Adv. Soil Sci. 1987, 6, 150-188.

38. Milne, A.; Ferguson, R.B.; Lark, R.M. Estimating a boundary line model for a biological response by maximum likelihood. Ann. Appl. Biol. 2006, 149, 223-234.

39. Mills, A.J.; Milewski, A.V.; Fey, M.V.; Gröngröft, A.; Peterson, A.; Sirami, C. Constraint on woody cover in relation to nutrient content of soils in western southern Africa. Oikos 2013, 122, 136-148.

40. Cabin, R.J. Science and resotarion under a big, demon haunted tent: A reply to Giardina et al. (2007). Restor. Ecol. 2007, 15, 377-381.

41. Cabin, R.J. Intelligent Tinkering: Bridging the Gap between Science and Practice; Island Press: Washington, DC, USA, 2011.

42. Murcina, C.; Aronson, J. Intelligent tinkering in ecological restoration. Restor. Ecol. 2014, 22, 279-283.

43. Giardina, C.P.; Litton, C.M.; Thaxton, J.M.; Cordell, S.; Hadway, L.J.; Sandquist, D.R. Science driven restoration: A candle in a demon haunted world-Response to Cabin (2007). Restor. Ecol. 2007, 25, 171-176. 
44. Kahneman, D.; Tversky, A. Intuitive prediction: Biases and corrective procedures. TIMS Stud. Manag. Sci. 1979, 12, 313-327.

45. Lovallo, D.; Kahneman, D. Delusions of success: How optimism undermines executives' decisions. Harv. Bus. Rev. 2003, 81, 56-63.

46. Buehler, R.; Griffin, D.; Ross, M. Inside the planning fallacy: The causes and consequences of optimistic time predictions. In Heuristics and Biases: The Psychology of Intuitive Judgment; Gilovich, T., Griffin, D., Eds.; Cambridge University Press: Cambridge, UK, 2002; pp. 250-270.

47. Michener, W.K. Quantitatively evaluating restoration experiments: Research design, statistical analysis, and data management considerations. Restor. Ecol. 1997, 5, 324-337.

48. Terziovski, M. Innovation practice and its performance implications in small and medium enterprises (SME's) in the manufacturing sector: A resource based view. Strateg. Manag. J. 2010, 31, 892-902.

49. Ebben, J.J.; Johson, A.C. Efficiency, flexibility, or both? Evidence linking strategy to performance in small firms. Strateg. Manag. J. 2005, 26, 1249-1259.

50. Massa, S.; Testa, S. Innovation and SMEs: Misaligned perspectives and goals among entrepreneurs, academics, and policy makers. Technovation 2008, 28, 393-407.

51. Amara, N.; Landry, R.; Becheikh, N.; Ouimet, M. Learning and novelty of innovation in established manufacturing SME's. Technovation 2008, 28, 450-463.

52. Smolin, L. The Trouble with Physics: The Rise of String Theory, the Fall of Science and What Comes Next; Houghton Mifflin Harcourt: New York, NY, USA, 2006.

53. Schulze, A.D.; Stade, M.J.C.; Netzel, J. Conflict and conflict management in innovation processes in the life sciences. Creativity Innov. Manag. 2014, 23, 57-75.

54. Drucker, P.E. The Effective Executive; Harper and Row: New York, NY, USA, 1967.

55. Blignaut, J.N.; Aronson, J.; de Wit, M. The economics of restoration: Looking back and leaping forward. Ann. N.Y. Acad. Sci. 2014, 1322, 35-47.

56. Mills, A.J.; Spear, D.; Ndhlovu, T.; Knight, M.H.; Pienke, D.M.; Hofmeyr, S.; Cowling, R.M. Biomass of large herbivores in South African subtropical thicket. Afr. J. Ecol. 2014, 52, 577-580.

57. Aronson, J.; Milton, S.J.; Blignaut, J. Restoring Natural Capital. Science, Business and Practice; Island Press: Washington, DC, USA, 2007.

58. Van Oosterzee, P.; Blignaut, J.; Bradshaw, C.J.A. iREDD hedges against avoided deforestation's unholy trinity of leakage, permanence and additionality. Conserv. Lett. 2012, 5, 266-273.

59. Blignaut, J.N.; van der Elst, L. Restoration of natural capital: Mobilising private sector investment. Dev. S. Afr. 2014, 31, 711-720.

(C) 2015 by the authors; licensee MDPI, Basel, Switzerland. This article is an open access article distributed under the terms and conditions of the Creative Commons Attribution license (http://creativecommons.org/licenses/by/4.0/). 